\title{
Caracterização de linhagens de tomateiro originadas de cruzamento interespecífico quanto à resistência à requeima
}

\author{
Cibelle VA Fiorini ${ }^{1}$; Derly José H da Silva²; Eduardo SG Mizubuti; Jordão de S Barros²; Laércio J da \\ Silva $^{2}$; Carla Milagres ${ }^{2}$; Murilo R Zaparoli ${ }^{4}$ \\ ${ }^{1}$ UFRRJ-Instit. Agronomia, Depto. Fitotecnia, BR 465 km 7, 23890-000 Seropedica-RJ; ${ }^{2,3}$ UFV-Dep ${ }^{\text {to }}$ Fitotecnia e Fitopatologia, 36570- \\ 000 Viçosa-MG; ${ }^{4} \mathrm{UFV}$, Engenheiro Agrônomo; cibellefiorini@yahoo.com.br; derly@ufv.br
}

\section{RESUMO}

O trabalho teve por objetivo identificar linhagens de tomateiro resistentes à requeima. Foram avaliados 72 genótipos de tomateiro (70 linhagens $\mathrm{F}_{8}$ mais os acessos do BGH-UFV '184' e '1497'). As linhagens originaram-se de cruzamento interespecífico entre Solanum lycopersicum ('Santa Clara') e Solanum habrochaites f. glabratum (acesso BGH-UFV '6902'). Os experimentos foram conduzidos em campo, em delineamento experimental de blocos casualizados, utilizando-se três e duas repetições no primeiro e segundo experimento, respectivamente. As plantas foram inoculadas com uma suspensão de esporângios de Phytophthora infestans provenientes de seis municípios produtores de tomateiro da Zona da Mata de Minas Gerais, na concentração de $10^{3}$ esporângios $\mathrm{mL}^{-1}$. Avaliou-se a porcentagem de severidade da doença, apresentada sob a forma de área abaixo da curva de progresso da doença (AACPD). Foram selecionadas, nos dois experimentos, 10 linhagens mais o acesso de tomateiro do BGH-UFV '1497'. As linhagens identificadas como 50 I, 90 J, 127 F, 145 B e $164 \mathrm{G}$ apresentaram valores médios de AACPD inferiores ao da testemunha resistente. Foi possível a introgressão de genes de resistência à requeima presentes em $S$. habrochaites $\mathrm{f}$. glabratum em S. lycopersicum.

Palavras-chave: Solanum spp., Phytophthora infestans, seleção, tomate, pré-melhoramento.

\begin{abstract}
Characterization of tomato lines originated of the interspecific cross with relationship to late blight resistance

In this research we evaluated tomato lines for resistance to late blight. An amount of 72 genotypes ( 70 tomato lines $\mathrm{F}_{8}$ plus the accesses of BGH-UFV '184'and '1497') was evaluated. The lines were derived from interspecific crossing between Solanum lycopersicum ('Santa Clara') and Solanum habrochaites f. glabratum (access BGH-UFV '6902'). The experiments were conducted in field in the randomized blocks design with two and three replications in the first and second experiment, respectively. The plants were inoculated with a sporangia blend of Phytophthora infestans from the six different tomato producing cities of Zona da Mata, Minas Gerais State, Brazil, in a concentration of $10^{3}$ sporangia $\mathrm{mL}^{-1}$. We evaluated the percentage of disease severity, presented as an area under the disease progress curve (AUDPC). In both experiments 10 tomato lines plus the access BGH-UFV '1497' were selected. The lines identified as $50 \mathrm{I}, 90 \mathrm{~J}, 127 \mathrm{~F}, 145 \mathrm{~B}$ and $164 \mathrm{G}$ presented medium values of AUDPC inferior to the resistant witness. It was possible the introgression of late blight resistance genes present in S. habrochaites f. glabratum in S. lycopersicum.
\end{abstract}

Keywords: Solanum spp., Phytophthora infestans, selection, tomato, pre-breeding.

(Recebido para publicação em 19 de março de 2009; aceito em 4 de maio de 2010) (Received on March 19, 2009; accepted on May 4, 2010)

\begin{abstract}
$\mathrm{A}^{\mathrm{n}}$ mela ou requeima, causada pelo oomiceto fitopatogênico Phytophthora infenstans (Mont.) De Bary, é considerada uma das doenças mais destrutivas para a cultura do tomateiro. Sob condições climáticas favoráveis, ou seja, temperaturas amenas (entre 15 e $20^{\circ} \mathrm{C}$ ) e umidade relativa superior a $85 \%$, pode afetar todos os órgãos aéreos do tomateiro: folhas, hastes, inflorescências e frutos verdes e maduros. Dependendo das condições climáticas e se medidas de controle não forem corretamente adotadas ocorre perda total da produção (Mizubuti, 2001; Mizubuti, 2005; Vale et al., 2007).

Atualmente, o manejo da requeima na cultura do tomateiro é feito exclusivamente pelo princípio de proteção do hospedeiro, através da aplicação de fungicidas de caráter preventivo e/ou
\end{abstract}

curativo, totalizando de 15 a 25 aplicações de fungicidas por safra (Costa et al., 2007). Segundo estimativas de economistas do Centro Internacional de La Papa, no Peru, mundialmente, são gastos cerca de um bilhão de dólares ao ano para o controle da requeima (Mizubuti, 2005).

Reis (2001) e Reis et al. (2006), em trabalhos realizados nas Regiões Sul, Sudeste e Centro-Oeste do Brasil, verificaram que as populações brasileiras de $P$. infestans apresentaram altas porcentagens de isolados resistentes e moderadamente resistentes ao metalaxyl (Ridomil® 2E) e mefenoxam (metalaxyl-m), importantes fungicidas que atuam no controle da requeima, principalmente quando as condições estão amplamente favoráveis à doença. Quanto ao espectro de virulência, verificado somente para as Regiões Sul e Sudeste, Reis (2001) constatou a ineficácia dos genes $P h_{1}$ e $\mathrm{Ph}_{2}$ em restringir o desenvolvimento de isolados de $P$. infestans, uma vez que a maioria dos isolados foram virulentos em plantas de tomateiro possuidoras dos genes $P h_{1}$ (cv. New Yorker) e $P h_{2}$ (cv. Caline).

Ainda, Reis (2001) verificou a existência de vários patótipos de $P$. infestans nas Regiões Sul e Sudeste do Brasil, concluindo que os programas de melhoramento genético para o tomateiro devem buscar a incorporação de resistência horizontal (duradoura) à requeima, bem como para outras doenças importantes da parte aérea, contribuindo para a diminuição do consumo de fungicidas, através da diminuição do número de pulverizações e/ou aumento dos intervalos entre estas. 
Sabe-se que um dos principais fatores limitantes ao cultivo do tomateiro são as doenças, principalmente quando não existem disponíveis no mercado cultivares com resistência genética (Vale et al., 2007). O uso de cultivares resistentes para controle de doenças é a estratégia mais eficaz e econômica, impedindo ou dificultando o estabelecimento do patógeno na lavoura. Nos dias atuais, além do aspecto econômico, o apelo mais expressivo para o uso de cultivares resistentes está relacionado à menor contaminação dos aplicadores de defensivos agrícolas, do solo e dos mananciais hídricos e à redução dos efeitos residuais nos alimentos, implicando diretamente em maior economia e segurança (Nojosa et al., 2004), além de possibilitar o cultivo orgânico do tomateiro.

As variedades e híbridos de tomateiro cultivados atualmente são suscetíveis à requeima (Mizubuti, 2005; Reis et al., 2006; Costa et al., 2007; Vale et al., 2007). Não há genótipos com boas características agronômicas e comerciais que apresentem nível satisfatório de resistência à requeima (Mizubuti, 2005). Segundo Tanksley (2002), é estimado que o genoma das cultivares comerciais de tomateiro contém menos de cinco por cento da variação genética total, em contrapartida às espécies silvestres.

Vários autores (Stevens \& Rick, 1986; Hallauer \& Miranda Filho, 1988; Melo, 1989; Vallois et al., 1996; Labory et al., 1999; Tanksley, 2002) enfatizam a restrita variabilidade genética do tomateiro cultivado, o que explica sua suscetibilidade às várias doenças e pragas, sugerindo a utilização em programas de melhoramento de genitores que possam contribuir para a ampliação da base genética dessa cultura, com genes de resistência ou tolerância às doenças, pragas, qualidade nutricional, entre outros, podendo selecionar tais genitores a partir de cultivares antigas da espécie cultivada ou mesmo de espécies silvestres pertencentes ao mesmo gênero.

De acordo com Laterrot (2000), a resistência a diversos patógenos é encontrada em espécies silvestres. Em programas de melhoramento visando resistência a doenças, a 'fonte de resistência' é um dos fatores mais importantes, devendo o melhorista realizar uma busca por genótipos resistentes em bancos de germoplasma (Abreu, 2005).

Borges et al. (2005) avaliaram 176 genótipos de tomateiro provenientes do Banco de Germoplasma de Hortaliças da Universidade Federal de Viçosa, verificando que apenas o acesso BGH-UFV '6902' (Solanum habrochaites f. glabratum) apresentou resistência à requeima. Abreu et al. (2008), em estudo sobre a herança da resistência à requeima em tomateiro, confirmaram ser essa do tipo poligênica, com aproximadamente vinte e oito genes controlando o caráter, bem como a resistência do acesso BGHUFV 6902 à requeima, o qual poderá constituir em nova fonte de resistência em trabalhos de melhoramento genético do tomateiro.

De acordo com Nass \& Paterniani (2000), pré-melhoramento é um conjunto de atividades que visam à identificação de caracteres e/ou genes de interesse presentes em materiais não adaptados (exóticos ou semi-exóticos) ou que ainda não foram submetidos a qualquer processo de melhoramento, para sua posterior incorporação nos materiais adaptados de elevado potencial produtivo (elites).

O presente trabalho faz parte de uma das etapas de um programa de pré-melhoramento para tomateiro e teve por objetivo a identificação linhagens resistentes à requeima.

\section{MATERIAL E MÉTODOS}

Os experimentos foram conduzidos em campo, na Horta de Pesquisa da Universidade Federal de Viçosa (UFV), em Viçosa (20 $45^{\prime} 14^{\prime}$ ' S; 42 $52^{\circ}$ ' 53'" $\mathrm{W} ; 648,74 \mathrm{~m}$ de altitude). Segundo a classificação de Köppen, o clima regional é do tipo Cwa, com umidade relativa média anual do ar de $80 \%$, temperaturas médias máxima e mínima anual registradas de 26,4 e $14,8^{\circ} \mathrm{C}$, respectivamente, e precipitação média anual de 1221,4 $\mathrm{mm}$.

Foram avaliados quanto à resistência à requeima 72 genótipos de tomateiro: 70 linhagens $\mathrm{F}_{8}$ e os acessos BGH-UFV 184 e 1497. As linhagens foram originadas de cruzamento interespecífico entre a cv. Santa Clara (S. lycopersicum L.) e o acesso BGH-UFV 6902 (S. habrochaites f. glabratum), conforme Figura 1, sendo o SSD (Single Seed Descent) o método utilizado no programa de melhoramento. O acesso BGH-UFV 6902, pertencente ao Banco de Germoplasma de Hortaliças da UFV, foi considerado por Borges et al. (2005) e Abreu et al. (2008) resistente à requeima; produz frutos pequenos de coloração esverdeada que, quando maduros, além de possuírem sabor e odor desagradáveis, não possuem características de interesse para comercialização. O acesso BGH-UFV 184 (S. lycopersicum L.), pertencente ao Banco de Germoplasma de Hortaliças da UFV, foi coletado em 1966 em Vitória de Santo Antão (PE); produz frutos predominantemente arredondados, biloculares, de coloração vermelha, cuja massa fresca média, teor de sólidos solúveis totais e produção é

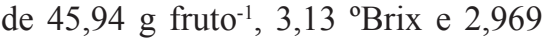
kg planta ${ }^{-1}$, respectivamente (www.ufv. br/bgh). O acesso BGH-UFV 1497 (S. lycopersicum L.), também pertencente ao Banco de Germoplasma de Hortaliças da UFV, foi coletado em 1967 na extinta Cooperativa Agrícola de Cotia (CAC), no estado de São Paulo; produz frutos do tipo Santa Cruz, arredondados, ligeiramente achatados, de coloração vermelha, cuja massa fresca média, teor de sólidos solúveis totais e produção é de $42,24 \mathrm{~g}_{\text {fruto }^{-1}}, 5,40{ }^{\circ}$ Brix e 2,631 $\mathrm{kg}$ planta $^{-1}$, respectivamente (www. ufv.br/bgh). Entre diversos acessos do BGH-UFV avaliados por Ribeiro et al. (2006), o 184 e 1497 se destacaram por possuírem bons níveis de resistência à requeima.

Devido à desuniformidade de germinação, crescimento e desenvolvimento das linhagens no decorrer do trabalho foram realizados dois experimentos independentes. Segundo Abreu (2005), em cruzamentos interespecíficos há muita ocorrência de falhas na geminação de sementes e não florescimento de algumas plantas, além da produção de sementes inviáveis. No primeiro experimento, conduzido entre setembro e novembro de 2006, foram avaliadas para resistência à requeima 23 linhagens $\mathrm{F}_{8}$ e os acessos de tomateiro do BGH-UFV 184 e 1497. No segundo experimento, conduzido entre março e maio de 2007 , foram ava- 
liadas 47 linhagens $\mathrm{F}_{8}$. A cultivar Santa Clara e o acesso BGH-UFV 6902 foram utilizados como testemunhas suscetível e resistente, respectivamente.

A semeadura foi feita em bandejas de isopor de 128 células contendo substrato comercial para hortaliças, semeando-se cinco sementes por célula. Após a germinação procedeu-se ao desbaste, deixando-se apenas uma plântula por célula. Ao apresentarem quatro folhas definitivas, as plântulas foram transferidas para copos plásticos descartáveis contendo substrato comercial para hortaliças, sendo mantidas em casa de vegetação até apresentarem oito folhas definitivas, momento em que foi realizado o transplantio para o campo, no espaçamento de $1,0 \times 0,5 \mathrm{~m}$.

Trinta dias após o transplante, as plantas foram inoculadas com uma mistura de esporângios provenientes de isolados de Phytophthora infestans patogênicos a tomateiro, na concentração de $10^{3}$ esporângios $\mathrm{mL}^{-1}$, coletados nos municípios mineiros de Cajuri, Coimbra, Ervália, Paula Cândido, Ponte Nova e Viçosa (Zona Rural e Horta de Pesquisa da UFV), conforme Fiorini (2008). Doze horas após a inoculação, com o intuito de garantir alta umidade ao ambiente, as plantas passaram a ser irrigadas por aspersão.

Três dias após a inoculação foram feitas as avaliações para resistência à requeima; realizaram-se seis avaliações, de três em três dias. Para as avaliações de severidade à requeima, os avaliadores foram submetidos a um treinamento mediante o uso do programa Severity PRO (Nutter, 1997), visando corrigir distorções inerentes à estimativa visual de severidade da doença. No campo, para cada folha de cada planta foram dadas notas de 0 a 100, estimando-se a porcentagem de tecido vegetal afetado pela doença, ou seja, a porcentagem de severidade da doença. A nota final de cada planta foi constituída pela média das notas de suas folhas. Em média foram avaliadas 25 folhas por planta.

Durante a condução dos experimentos, as plantas foram irrigadas e adubadas regularmente, recebendo os tratos normais da cultura, como desbrotas, amarrios e tratamentos fitossanitários. Os tratamentos fitossanitários foram interrompidos dez dias antes da inoculação e durante as avaliações para resistência à requeima. Deixou-se apenas uma haste por planta. Plantas da cv. Santa Clara foram utilizadas como bordadura.

No primeiro experimento, o delineamento experimental foi de blocos casualizados, com três repetições e cinco plantas por parcela. No segundo experimento também foi utilizado o delineamento em blocos casualizados, porém com duas repetições e cinco plantas por parcela. As análises estatísticas, as quais constaram da análise de variância e seleção entre famílias, foram realizadas com o auxílio do programa computacional GENES (Cruz, 2001). Foram analisados os valores médios de porcentagem de severidade da doença, apresentados sob a forma de área abaixo da curva de progresso da doença (AACPD), como descrito por Campbell \& Madden (1990). A seleção para resistência à requeima foi feita no sentido negativo, ou seja, quanto menor a AACPD maior o grau de resistência do genótipo.

\section{RESULTADOS E DISCUSSÃO}

Nos dois experimentos, foi possível identificar o início da doença 3 a 6 dias após a inoculação, com plantas apresentando geralmente menos de $1 \%$ do tecido vegetal afetado. No primeiro experimento, entre os dias 09 e 27 de outubro de 2006, período entre a inoculação e avaliações para resistência à requeima, o município de Viçosa-MG apresentou temperaturas médias máxima e mínima de 25,7 e $17,2^{\circ} \mathrm{C}$, respectivamente, umidade relativa média de $81 \%$ e precipitação de $146,2 \mathrm{~mm}$. No segundo experimento, entre os dias 02 e 20 de maio de 2007, as temperaturas médias máxima e mínima foram de 26,3 e $12,2^{\circ} \mathrm{C}$, respectivamente, e a umidade relativa média de $80 \%$, não havendo chuvas durante o período no município. Tais valores, relacionados às variáveis climáticas, são considerados adequados ao desenvolvimento $P$. infestans no campo (Mizubuti, 2005).

Para os dois experimentos foram observadas diferenças significativas $(\mathrm{p}<0,01)$ quanto à resistência à requeima entre os genótipos avaliados. Verificouse que as testemunhas suscetível e resistente, cv. Santa Clara e acesso BGH-UFV 6902, respectivamente, apresentaram valores médios extremos de AACPD, correspondentes à maior suscetibilidade (cv. Santa Clara) e maior resistência (acesso BGH-UFV 6902). No primeiro experimento, as médias de AACPD dos genótipos avaliados e das testemunhas suscetível e resistente foram 250, 447 e 168, respectivamente. No segundo experimento, as médias de AACPD dos genótipos avaliados e das testemunhas suscetível e resistente foram 44, 282 e 23, respectivamente. Através das médias de AACPD obtidas nos dois experimentos, observou-se que os genótipos avaliados se comportaram entre os genitores suscetível e resistente, porém com tendência de maior aproximação do genitor resistente.

Os resultados obtidos nos dois experimentos seguiram a mesma tendência dos resultados obtidos por Abreu (2005) e Abreu et al. (2006) e já eram esperados, visto que as setenta linhagens de tomateiro avaliadas nos presentes experimentos já haviam sido selecionadas, na geração $\mathrm{F}_{5}$, para resistência à requeima, pelo mesmo autor.

Abreu et al. (2008), em estudo realizado sobre herança da resistência à requeima em tomateiro, observaram a ocorrência de dominância no sentido da suscetibilidade controlando o caráter, além de baixas herdabilidades, da ordem de $54,86 \%$ e $9,06 \%$ para herdabilidades no sentido amplo e restrito, respectivamente. Concluíram que a herança da resistência à requeima é do tipo poligênica, com aproximadamente vinte e oito genes controlando o caráter.

De acordo com Allard (1971) e Ramalho et al. (2000), muitos genes envolvidos no controle de características quantitativas podem não ter efeitos isolados, além de serem altamente influenciados pelo ambiente. Ao comparar as médias de AACPD dos genótipos avaliados e das testemunhas suscetível (cv. Santa Clara) e resistente (acesso BGH-UFV 6902) obtidas nos dois experimentos, verificou-se que essas, no primeiro experimento, foram elevadas, fato esse explicado pela precipitação e 
S. lycopersicum L. cv. Santa Clara x S. habrochaites f. glabratum acesso BGH-UFV '6902’

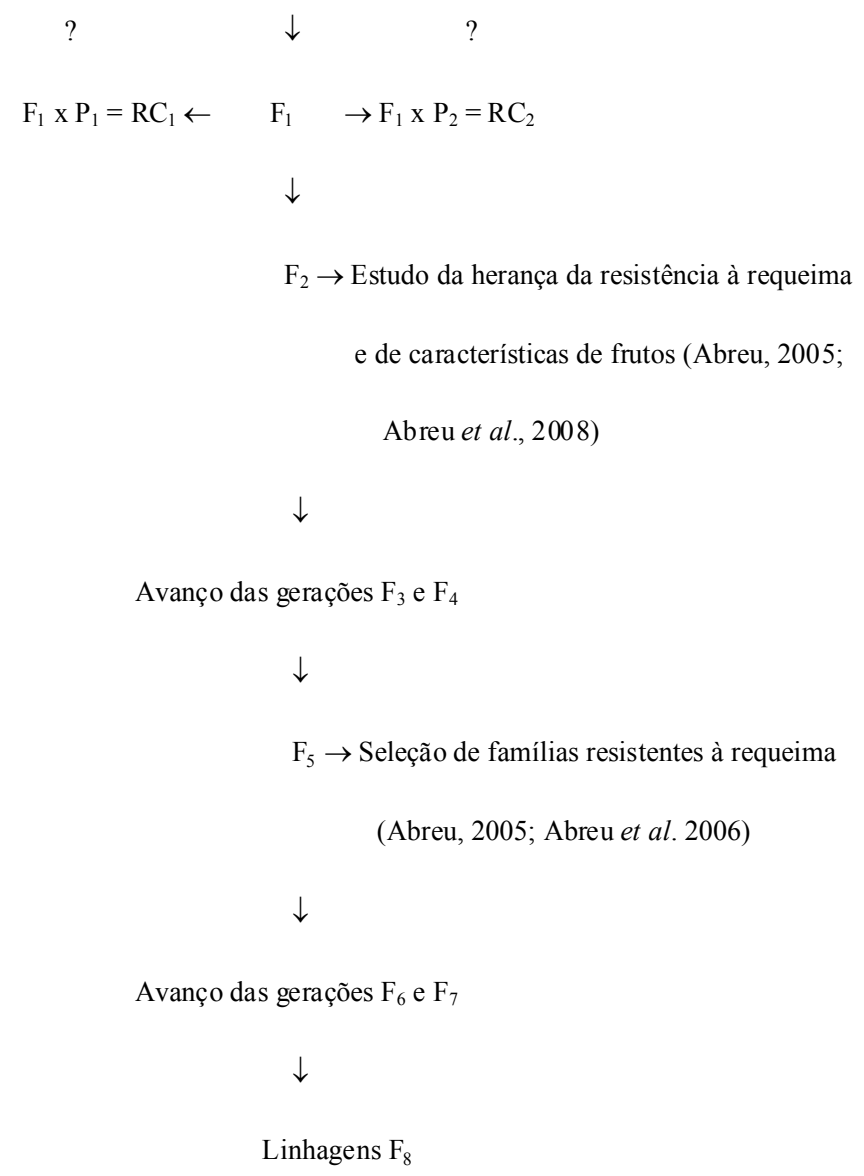

Figura 1. Origem das linhagens $\mathrm{F}_{8}$ de tomateiro do programa de pré-melhoramento visando resistência à requeima (origin of pre-breeding program tomato lines for late blight resistance). Viçosa, UFV, 2006.

irrigação. Os experimentos, até as datas anteriores às inoculações, foram irrigados com mangueira. Após, passaram a ser irrigados por aspersão, visto que a umidade desempenha papel importante no progresso da doença. No primeiro experimento, além da temperatura ter favorecido a infecção e o desenvolvimento do patógeno, a ocorrência de chuvas no município e a irrigação por aspersão, programada para ser ligada de uma em uma hora por dez minutos, permitiu rápido desenvolvimento de $P$. infestans; inclusive, na quarta avaliação, várias plantas da cv. Santa Clara apresentaram nota máxima para porcentagem de severidade da doença. No segundo experimento, apesar da temperatura favorável à infecção e ao desenvolvimento do patógeno, não houve chuvas no município e a irrigação por aspersão, devido ao intenso ataque de $P$. infestans ocorrido no primeiro experimento, foi programada para ser ligada somente três vezes ao dia (9:00h, 14:00h e 17:00h) por quinze minutos. Sendo a requeima uma doença dependente das condições climáticas, a temperatura média de $21,45^{\circ} \mathrm{C}$ e a elevada umidade ocorrida durante as avaliações do primeiro experimento permitiram rápido desenvolvimento do patógeno, proporcionando, conseqüentemente, elevados valores médios para AACPD.

Tanto no primeiro quanto no segundo experimento foram selecionadas cinco linhagens resistentes à requeima. No primeiro experimento, além das cinco linhagens, identificadas como 127 F, 64 B, 73 A, 163 A e 133 A, também foi selecionado o acesso de tomateiro do BGH-UFV 1497. No segundo expe- rimento foram selecionadas as linhagens 164 G, 145 B, 50 I, 90 J e 170 C.

As linhagens 127 F, 164 G, 145 B, $50 \mathrm{I}$ e $90 \mathrm{~J}$ apresentaram valores médios de AACPD inferiores ao da testemunha resistente (acesso BGH-UFV 6902) (Figuras 2 e 3). Entre diversos acessos do BGH-UFV avaliados por Ribeiro et al. (2006), o 184 e 1497 se destacaram, por possuírem bons níveis de resistência à requeima. No presente trabalho destacou-se somente o acesso BGHUFV 1497, o qual apresentou média de AACPD igual a da testemunha resistente (Figura 2).

Foi observado que, em relação à testemunha suscetível 'Santa Clara', tais linhagens mais o acesso BGH-UFV 1497 apresentaram bons níveis de resistência à requeima. No primeiro experimento foi observado o valor médio de AACPD de 447 para a testemunha suscetível 'Santa Clara', a qual apresentou diferença de 212 unidades em relação ao valor médio de AACPD observado para a linhagem 133 A (linhagem selecionada para resistência à requeima de menor valor médio de AACPD, da ordem de 235). No segundo experimento, o valor médio de AACPD observado para a cv. Santa Clara foi 282, apresentando diferença de 258 unidades em relação ao valor médio de AACPD observado para a linhagem $170 \mathrm{C}$ (linhagem selecionada para resistência à requeima de menor valor médio de AACPD, da ordem de 24) (Figuras 2 e 3).

Ewing et al. (2000), trabalhando com populações de batata originadas de cruzamentos interespecíficos entre Solanum tuberosum e S. berthaultii, verificaram que introgressões de genes de resistência à requeima presentes em $S$. berthaultii possibilitaram reduções nos níveis de desenvolvimento da doença, sendo observadas diferenças de AACPD entre progênies de 175 para mais de 400 unidades. De acordo com esses autores, para a cultura da batata, diferenças de AACPD de até 200 unidades apresentam impactos significativos no desenvolvimento da epidemia e requerimento de tempo de aplicação de fungicida. Para a cultura do tomateiro, ainda são necessários estudos para estabelecer valores de AACPD que apresentem resultados no controle da requeima. 


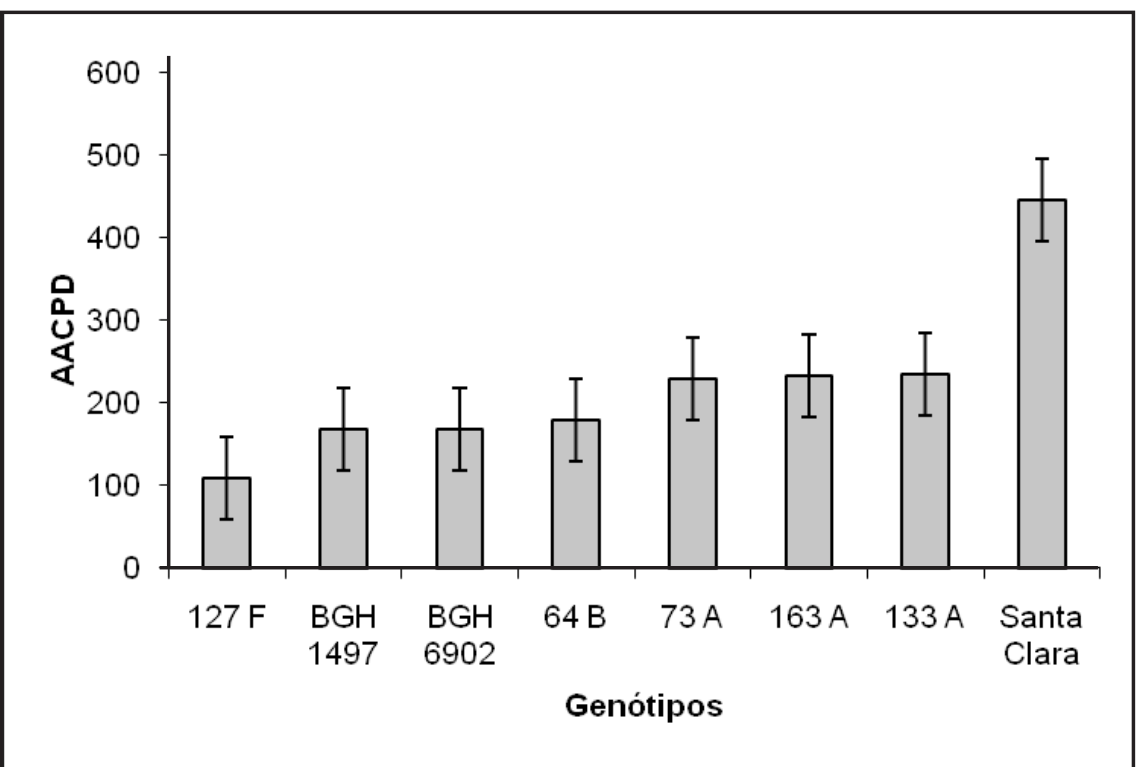

Figura 2. Valores médios de área abaixo da curva de progresso da doença (AACPD) em cinco linhagens de tomateiro selecionadas para resistência à requeima, na cv. Santa Clara e nos acessos BGH-UFV '6902' e '1497' (average values of area under the disease progress curve (AACPD) in five tomato lines selected to late blight resistance, in cv. Santa Clara and accessions BGH-UFV ‘6902’ and '1497’). Viçosa, UFV, 2006.

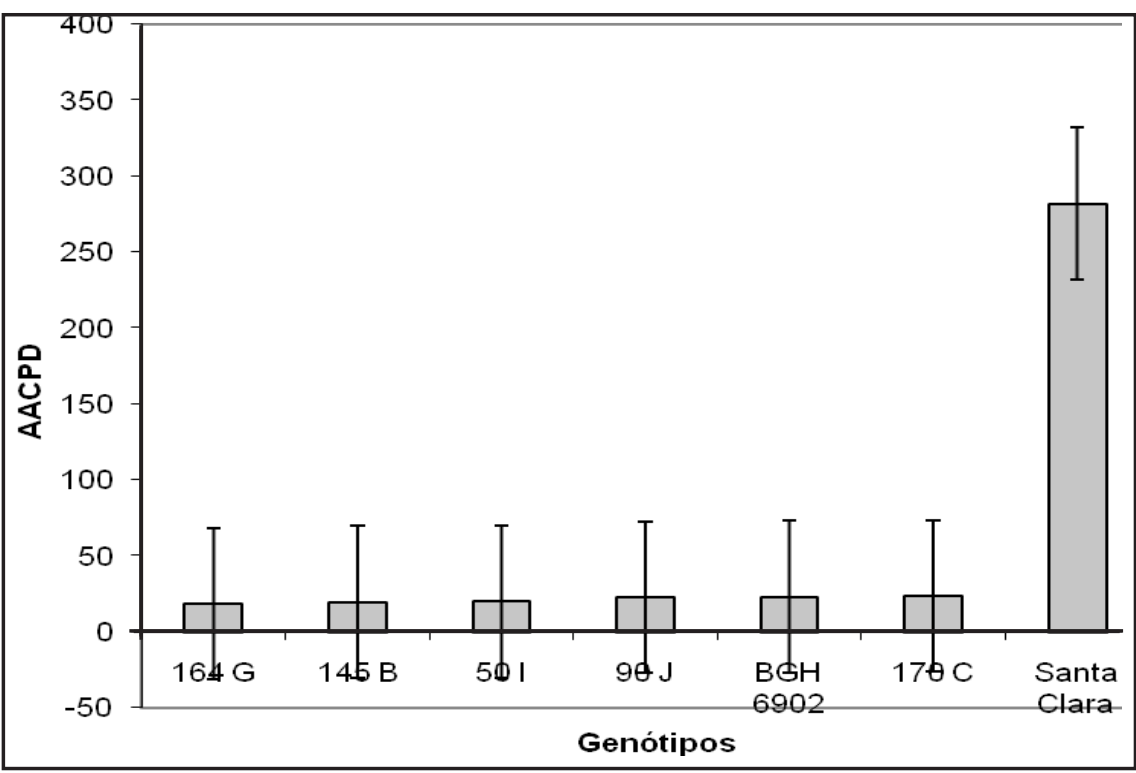

Figura 3. Valores médios de área abaixo da curva de progresso da doença (AACPD) em cinco linhagens de tomateiro selecionadas para resistência à requeima, na cv. Santa Clara e no acesso BGH-UFV '6902' (average values of area under the disease progress curve (AACPD) in five tomato lines selected to late blight resistance, in cv. Santa Clara and accession BGH-UFV '6902'). Viçosa, UFV, 2007.

Observou-se que no presente trabalho foi possível a introgressão de genes de resistência à requeima presentes em Solanum habrochaites em S. lycopersicum. Foram observadas diferenças significativas quanto à AACPD entre a cultivar Santa Clara e as linhagens de tomateiro selecionadas para resistência à requeima, podendo-se inferir que tais linhagens possuem genes de resistência à requeima. As linhagens selecionadas poderão possibilitar o desenvolvimento de cultivares de tomateiro resistentes à requeima, acarretando em menores níveis de desenvolvimento da doença no campo e, consequentemente, contribuindo para a diminuição do uso de fungicidas, através da diminuição da quantidade e/ou número de pulverizações.

\section{AGRADECIMENTOS}

Os autores agradecem à CAPES, CNPq, FAPEMIG e UFV, pelo auxílio financeiro e suporte necessário à realização desse trabalho. À CAPES e CNPq, pela bolsa de doutorado da primeira autora.

\section{REFERÊNCIAS}

ABREU FB. 2005. Herança da resistência a Phytophthora infestans, de características de frutos e seleção de genótipos resistentes na geração $F_{5}$ de cruzamento interespecifico em tomateiro. Viçosa: UFV. 95 p (Tese doutorado).

ABREU FB; SILVA DJH; LOOS R; FIORINI CVA; LOPES J; MIZUBUTI ESG; CRUZ CD. 2006. Seleção de genótipos de tomateiro resistentes a Phytophthora infestans em famílias $\mathrm{F}_{5}$. In: CONGRESSO BRASILEIRO DE OLERICULTURA, 46. Resumos... Goiânia: ABH (CD-ROM).

ABREU FB; SILVA DJH; CRUZ CD; MIZUBUTI ESG. 2008. Inheritance of resistance to Phytophthora infestans (Peronosporales, Pythiaceae) in a new source of resistance in tomato (Solanum sp. (formerly Lycopersicon sp.), Solanales, Solanaceae). Genetics and Molecular Biology 31: 493-497.

ALLARD RW. 1971. Principios do melhoramento genético das plantas. São Paulo: Edgard Blucher. $381 \mathrm{p}$.

BORGES MF; MARCHI CE; MIZUBUTI ESG; SILVA DJH. 2005. Reação de genótipos de Lycopersicon à Phytophthora infestans. Summa Phytopathologica 31, suplemento, p 53.

CAMPBELL CL; MADDEN LV. 1990. Introduction to plant disease epidemiology. New York. John Wiley \& Sons. 532 p.

COSTA H; ZAMBOLIM L; VETURA JA. 2007. Doenças de hortaliças que se constituem em desafio para o controle. In: ZAMBOLIM L; LOPES CA; PICANÇO MC; COSTA H (eds). Manejo integrado de doenças e pragas - hortaliças. Viçosa: UFV. p. 319-348.

CRUZ CD. 2001. Programa Genes (versão Windows): aplicativo computacional em genética e estatística. Viçosa: UFV. 648 p.

EWING EE; SIMKO I; SMART CD; BONIERBALE MW; MIZUBUTI ESG; MAY GD; FRY WE. 2000. Genetic mapping from field tests of qualitative and quantitative resistance to Phytophthora infestans in a population derived from Solanum tuberosum and Solanum berthaultii. Molecular Breeding 6: 25-36.

FIORINI CVA. 2008. Introgressão de genes de resistência à requeima de Solanum habrochaites em Solanum lycopersicum. Viçosa: UFV. 163 p (Tese doutorado).

HALLAUER AR; MIRANDA FILHO JB. 1988. Quantitative genetics in maize breeding. 
Ames: Iowa State University Press. 468 p. LABORY CRG; SANTA-CECÍLIALVC; MALUF WR; CARDOSO MG; BEARZOTTI E; SOUZA JC. 1999. Seleção indireta para teores de 2-tridecanona em tomateiros segregantes e sua relação com a resistência à traça do tomateiro. Pesquisa Agropecuária Brasileira 34: 723-739.

LATERROT H. 2000. Disease resistance in tomato: pratical situation. Acta Physiologiae Plantarum 22: 328-331.

MELO PCT. 1989. Melhoramento genético do tomateiro (Lycopersicon esculentum Mill.). Campinas: Asgrow do Brasil Sementes Ltda. $55 \mathrm{p}$.

MIZUBUTI ESG. 2001. Requeima ou mela da batata e do tomate. In: LUZ EDMN; SANTOS AF; MATSUOKA K; BEZERRA JL. (eds). Doenças causadas por Phytophthora no Brasil. Campinas: Livraria Editora Rural. p. 100-174.

MIZUBUTI ESG. 2005. Custo da requeima. Cultivar-Hortaliças e Frutas. 32: 23-26.

NASS LL; PATERNIANI E. 2000. Pre-breeding: a link between genetic resources and maize breeding. Scientia Agricola 57: 581-587.

NOJOSA GBA; FARIA MV; SILVA LHCP. 2004.

Melhoramento genético visando o controle de doenças. In: SILVA LHCP; CAMPOS JR; NOJOSA GBA. (eds). Manejo integrado de doenças e pragas em hortaliças. Lavras: UFLA. p. 241-243.

NUTTER JRFW. 1997. Disease severity assessment training. In: FRANCL LJ; NEHER DA. (eds). Exercises in plant disease epidemiology. St. Paul: The American Phytopatological Society Press. p. 1-7.

RAMALHO MAP; SANTOS JB; PINTO CABP. 2000. Genética na Agropecuária. Lavras: Editora UFLA. 472 p.

REIS A. 2001. Caracterização das populações de Phytophthora infestans das regiões Sul e Sudeste do Brasil. Viçosa:UFV. 76 p (Tese doutorado).

REIS A; RIBEIRO FHS; MIZUBUTI ESG. 2006. Caracterização de isolados de Phytophthora infestans do Distrito Federal e de Goiás. Fitopatologia Brasileira 31: 270-276.
RIBEIRO NB; RODRIGUES GS; BARRA VR; SILVA DJH; MIZUBUTI ESG. 2006. Desempenho de acessos de tomateiro do Banco de Germoplasma de Hortaliças da UFV, quanto à resistência a Phytophthora infestans. Summa Phytopathologica 32, suplemento, p. 9-98, resumo 53

STEVENS MA; RICK CM. 1986. Genetics and breeding. In: ATHERTON JG; RUDISH J. (eds). The tomato crop. Cambridge: Chapman and Hall. p. 35-110.

TANKSLEY SD. 2002. The genetic, developmental, and molecular bases of fruit size and shape variation in tomato. The Plant Cell 16: 181-189.

VALE FXR; JESUS JÚNIOR WC; RODRIGUES FA; COSTA H; SOUZA CA. 2007. Manejo de doenças fúngicas em tomateiro. In: SILVA DJH; VALE FXR. Tomate: tecnologia de produção. Viçosa: UFV. p. 159-197.

VALLOIS ACC; SALOMÃO AN; ALLEM AC. 1996. Glossário de recursos genéticos vegetais. Brasília: SPI. 62 p. 